\title{
Del federalismo al nacionalismo electoral
}

\section{From Federalism to Electoral Nationalism}

\section{Javier Santiago Castillo*}

\section{Sumario:}

I. Preámbulo

II. Los hilos del federalismo reformado

III. Vinculación entre el Instituto Nacional Electoral y los organismos públicos locales electorales

IV. Reflexiones finales

V. Bibliografía

* Consejero electoral del Instituto Nacional Electoral (INE); candidato a doctor en Ciencia Política por la Facultad de Ciencias Políticas y Sociales, UNAM, y licenciado en Ciencias Políticas y Administración Pública por la misma universidad; profesorinvestigador en la Universidad Autónoma Metropolitana, Iztapalapa, con licencia; consejero presidente del Instituto Electoral del Distrito Federal, 1991-2005.

Recibido: 9 de agosto de 2014 Aceptado: 8 de diciembre de 2014 


\section{Resumen:}

La reforma político electoral de 20132014 generó un debate en torno a federalizar o centralizar las funciones del modelo electoral mexicano. La disputa entre ampliar las facultades del Instituto Federal Electoral o crear un nuevo paradigma centralizado para la administración de las elecciones, se trasformó en un modelo hibrido con atribuciones concurrentes entre el Instituto Nacional Electoral (INE) y los Organismos Públicos Locales Electorales (OPLES), donde la soberanía estatal y el carácter autónomo de los poderes públicos locales se ven mermados. El objetivo del presente trabajo es señalar los ámbitos de competencia de cada uno y distinguir las injerencias de la esfera electoral federal en el ámbito estatal y nacional.

\begin{abstract}
:
The political and electoral reform of 2013-2014 generated a debate between a federal or centralized electoral model in Mexico. The dispute between extending the Federal Electoral Institute's power, or creating a new centralized paradigm for the management of the elections, resulted into a hybrid model with concurrent powers between the National Electoral Institute (INE, for its acronym in Spanish) and Electoral Local Public Organisms (OPLES, for its acronym in Spanish), where state sovereignty and the autonomy of local authorities is diminished. The purpose of this study is to identify the areas of competence of each one and distinguish the interference of the federal electoral area in the state and national level.
\end{abstract}

Palabras clave: federalismo electoral, Instituto Nacional Electoral, organismos públicos locales electorales, reforma electoral, competencias electorales.

Key words: electoral federalism, National Electoral Institute, electoral local public organisms, electoral reform, electoral competitions. 


\section{Preámbulo}

El sistema electoral mexicano se ha caracterizado por un ciclo de crisis políticas y reformas electorales que han configurado la representación política y el acceso al poder en nuestro país. Este ciclo inició con las reformas liberalizadoras al sistema electoral mexicano, a finales de la década de los setenta; transitó por varias etapas en las que fue adquiriendo diversas características; y culminó con la reforma constitucional en materia político electoral de 2013-2014, la cual transformó, no solo el modelo electoral, sino el sistema federal y el equilibrio político en el país.

Si bien, en términos generales, podemos afirmar que han existido tres modelos electorales (1824-1946; $\left.{ }^{1} 1946-1990 ;{ }^{2} 1990-2014\right)$, es hasta con el modelo electoral 1990-1996 que se establecen los rasgos esenciales del sistema electoral autónomo, donde el denominador común es la clara definición de competencias en la organización de las elecciones federales y locales, y la autonomía e independencia en torno a las decisiones de los organismos electorales.

Derivado del conflicto poselectoral de 1988 nace el Instituto Federal Electoral (IFE); institución, formalmente autónoma, pero con controles gubernamentales que acotaban su independencia tanto del Poder Ejecutivo como del Legislativo. Este arreglo institucional fue insuficiente, de modo que para 1994 la creciente demanda de imparcialidad condujo a su transformación; con la presencia de los consejeros ciudadanos pero aún con un fuerte control gubernamental, pues era presidida por el secretario de gobernación.

1 Durante este periodo, la materia electoral que formó parte de la jurisdicción constitucional se refería a los requisitos para ser postulado a un puesto de elección popular y la integración de los poderes del Estado, siendo las autoridades municipales las encargadas de organizar las elecciones federales. Esto último quedó establecido en las leyes electorales de 1911 y de 1918.

2 Con la Ley Electoral Federal de 1946 se crea un organismo federal, organizador de las elecciones (Comisión Federal de Vigilancia Electoral) y se abre un nuevo periodo en la vida electoral del país. Dicho órgano era dominado por el Ejecutivo Federal y era cúspide de la pirámide de la estructura electoral que se desdoblaba en 32 comisiones locales electorales y en los comités electorales distritales. Asimismo, esta ley reconoce la existencia de una forma de gobierno federal, por lo que delega a los poderes locales la atribución de legislar en la materia electoral; atribución que no constituía una garantía de autonomía. Este modelo, con diferencias, estuvo vigente hasta 1990 cuando nació el Instituto Federal Electoral, derivado de la reforma al artículo 41 constitucional. 
Dicha cuestión se modificó con la reforma constitucional de 1996 que originó un modelo autonomista ${ }^{3}$ de una administración de lo electoral con las siguientes características: a) la constitución de una autoridad electoral de carácter permanente, dotada de autonomía respecto de los poderes públicos, cuyo órgano superior de dirección se encontraba integrado por ciudadanos apartidistas; $b$ ) la desaparición del procedimiento de "autocalificación de la elección", para depositarlo en un órgano jurisdiccional plenamente autónomo e independiente; $c$ ) la creación de un cuerpo profesional de funcionarios encargados de la organización de los procesos de elección de gobernantes y representantes populares y de las cuestiones jurisdiccionales atinentes a la materia electoral, y $d$ ) el perfeccionamiento del federalismo electoral mediante el mandato constitucional de constituir en cada entidad federativa, órganos análogos al Instituto Federal Electoral.

La identificación de esta característica dual es indispensable, en la medida que permite observar cómo se cierra la etapa de un modelo electoral autónomo ampliamente federalista, que contaba con la existencia de un organismo electoral federal y otros treinta dos en las entidades federativas, y se abre una nueva etapa en la vida electoral de México, que acota la soberanía estatal y el carácter autónomo de los institutos electorales locales. La disputa entre el modelo federalista descentralizado y la creación un nuevo paradigma centralizado para la administración de las elecciones, tanto en sus aspectos organizacionales como en las relaciones entre instituciones y órdenes de gobierno, culminó en un modelo híbrido con atribuciones exclusivas y concurrentes entre el Instituto Nacional Electoral y los organismos públicos locales electorales. ${ }^{3}$ Desde esta mirada, el objetivo de este trabajo es señalar los replanteamientos de los ámbitos de competencia de los organismos nacionales y locales, y distinguir la participación de la autoridad electoral federal en los ámbitos electorales estatales.

3 Cabe recordar que la propuesta de crear un Instituto Nacional de Elecciones no es nueva, pues ya en tres ocasiones anteriores ha sido traída a la mesa de las reformas políticas. La primera fue en 2001 cuando el Partido de la Revolución Democrática (PRD) lo incluyó en su Programa de Acción. La segunda ocurrió durante la reforma político electoral 2007-2008, donde el tema fue abanderado por los partidos del PRI, PRD, PVEM, PT y Convergencia. Finalmente, en su iniciativa de reforma política 2010, el PAN se manifestó por su inclusión. Actualmente, el Pacto por México ha resucitado el tema al proponer, como parte de la agenda a discusión: "Crear una autoridad electoral de carácter nacional y una legislación única, que se encargue tanto de las elecciones federales, como de las estatales y municipales". Cfr. "Acuerdos para la gobernabilidad democrática", Pacto por México. Acuerdos, p. 18. 


\section{Los hilos del federalismo reformado}

El proyecto político del siglo XIX era construir un poder central, lo suficientemente fuerte, como para aglutinar en sí a todos los elementos tradicionales ${ }^{4}$ que tendían a la disgregación; se buscaba entonces, entramar y subordinar en un poder nacional todos los niveles de vida social, incluidos en ellos, los poderes regionales. ${ }^{5} \mathrm{Si}$ bien las constituciones de 1824 y $1857^{6}$ establecieron las bases federales del Estado mexicano, fue hasta entrado el siglo XX cuando la disputa entre federalismo como medio para consolidar la unidad nacional o federalismo como medio de reivindicación de las particularidades ${ }^{7}$ quedó resuelta y, posteriormente, expuesta a los controles del poder presidencial. Acepciones a las que se añade una doble tensión: a la concepción de federalismo como unidad nacional se une la oposición federalismo vs centralismo; mientras que a la noción federalismo como reivindicación de las particularidades, se une la de libertad $v s$. poder. $^{8}$

La primera tensión hace referencia a las discusiones que se dieron durante el constituyente de 1857 sobre cuál modelo de gobierno adoptar para consolidar el Estado nacional mexicano. Las deliberaciones se centraron entre instituir un gobierno central que controlara todas las aristas

4 Entre los elementos tradicionales que tendían a la disgregación se encuentran los poderes regionales y caciquiles que concentraban en sus manos las riendas del poder económico y político del país, sobre todo en un momento donde existía un Estado nacional sin control efectivo de la población y el territorio, sin autoridad ni contenido por poderes locales dominando a los centrales. Cfr. Córdova, Arnaldo, La formación del poder político en México, México, Era, 1978.

5 Mauricio Merino argumenta que "los municipios fueron aliados del centralismo político mexicano... en ese proceso constructivo, al ofrecer lo que podría llamarse la "infraestructura política" para la edificación de las instituciones nacionales". Merino, Gobierno local, poder nacional. La contienda por la formación del Estado mexicano, México, El Colegio de México, 2005, pp. 14-18.

6 Durante este periodo, ocurrieron dos momentos en los que la tendencia centralista se impuso: 1836 y 1842, donde ante presiones de los grupos conservadores de este país, fueron decretadas, modificaciones sustanciales a la Constitución de 1842, adoptándose un régimen de gobierno centralista.

7 Reyes Heroles, Jesús, “El federalismo”, El liberalismo mexicano, III. La integración de las ideas, México, FCE, 2007, p. 339.

8 Hernández Chávez, Alicia, "Las tensiones internas del federalismo mexicano", ¿Hacia un nuevo federalismo?, México, FCE, 1996, p. 16. 
del ejercicio del poder político y económico, o bien varios centros organizativos, en una especie de descentralización, que tuvieran facultades delimitadas. Sin embargo, la cuestión de fondo era cómo lograr conciliar la pluralidad política existente en el país, qué modelo de gobierno serviría para construir la nación y, aún más, cómo limitar la actuación de las partes (estados y municipios) en aras de la paz nacional.

Por su parte, la segunda se refiere a cómo aglutinar el ejercicio del poder y limitar la libertad política, es decir, ¿quién detentaría el poder político, la federación o los polos regionales que la conformaban? Ambas tensiones nos sirven para explicar el ulterior funcionamiento del federalismo mexicano, sobre todo, en su adaptación al régimen posrevolucionario, la subordinación de los gobiernos locales al poder político del centro y, finalmente, las reivindicaciones que desde lo local se dieron en torno a la democracia.

Resulta que, en la práctica, el federalismo mexicano terminó por privilegiar una visión de un federalismo como medio para consolidar la unidad nacional, e incluyó en él ambas tensiones; por un lado, construyó un poder central que concentró cualquier ejercicio del poder político, $y$, por el otro, limitó la libertad de las particularidades que conformaban la federación, mermando así el modelo federal clásico al actuar con un centralismo a ultranza que restringía cualquier expresión de autonomía. Es así como la acepción del federalismo como "un afianzamiento unitario de colectividades con derecho a la autodeterminación, [en una] reducción de facultades de las entidades federadas en aras de la unidad que ellas en su conjunto deben constituir", 9 quedó disminuida a su mínima expresión, es decir, solo en el acuerdo constitucional de $1917 .{ }^{10}$

En términos de Luis Medina, entre el sistema político del siglo XIX y el XX existe una serie de continuidades que permitieron confeccionar las instituciones que organizaron la vida política mexicana. El continuum entre uno y otro se encuentra en el modelo, es decir, en el arreglo constitucional, y no en la puesta en práctica, ya que, mientras la Constitución de 1857 se enfocaba en lograr la felicidad de la nación solo con el diseño de la forma óptima de gobierno, en 1917 aparece la necesidad de construir acuerdos y reglas informales para la operación política del sis-

9 Reyes Heroles, Jesús, op. cit., p. 343.

10 La Constitución de 1917 establece en su artículo 40 que: "Es voluntad del pueblo mexicano constituirse en una república representativa, democrática, federal compuesta de estados libres y soberanos en todo lo concerniente a su régimen interior; pero unidos en una federación establecida según los principios de esta ley fundamental”. 
tema. Continuidad que no se presenta, de igual manera, si comparamos el Porfiriato respecto al régimen posrevolucionario, en el sentido de que el régimen posrevolucionario no se contrapone al Porfiriato, de hecho el sistema político posrevolucionario corrigió los principales defectos del sistema político del Porfiriato, éste logró consolidar no solo un Estado nacional que aglutinaría a las fuerzas políticas del país, sino también estableció, a través de reglas formales e informales, las estructuras del poder personal que concentraría en sus manos el poder nacional. ${ }^{11}$

El régimen posrevolucionario consolidó la institución partido-gobierno, bajo una lógica dual de correspondencia, que para finales de 1940, instauró dos tendencias que facultarían el acceso al poder dentro del sistema político mexicano: $a$ ) el predominio del Ejecutivo respecto a los otros poderes (Legislativo y Judicial), y b) la imposición de la federación sobre los estados y municipios. La dinámica partido-gobierno ${ }^{12}$ estableció un federalismo jerárquico, en el cual la relación entre niveles de gobierno se dio de manera subordinada: "Los gobiernos municipales están subordinados en buena parte a los gobiernos estatales, y éstos a su vez al gobierno federal", ${ }^{13}$ alejándonos de la idea de estados libres y soberanos, en donde pueda establecerse un federalismo tripartito. ${ }^{14}$

11 Cfr. Medina Peña, Luis, Invención del sistema político mexicano. Forma de gobierno y gobernabilidad en México en el siglo XIX, México, FCE, 2007, y Córdova, Arnaldo, La formación del poder político en México, cit., 1978.

12 Cuando hacemos referencia a la dinámica partido-gobierno queremos explicitar que entre la Presidencia de la República y el Partido Revolucionario Institucional (PRI), el partido oficial, existía una lógica de reciprocidad, en la cual el PRI asegura el acceso a los cargos públicos, mientras el presidente controlaba los hilos del ejercicio gubernamental.

13 Cfr. Cabrero Mendoza, Enrique, "El panorama de la descentralización en México: ¿hacia qué tipo de federalismo evolucionar?", Avances y pendientes para fortalecer el federalismo, México, CESOP, 2007, p. 25, y Cabrero Mendoza, Enrique, Para entender el federalismo en los Estados Unidos Mexicanos, México, Ediciones Nostra, 2007.

14 Deil S. Wrigt propuso un enfoque para el estudio de las relaciones intergubernamentales basándose en la evolución del federalismo norteamericano, el cual sugiere tres modelos: 1) el modelo de autoridad coordinada (relaciones interdependientes-patrones de autoridad autónomos); 2) el modelo de autoridad traslapada (relaciones interdependientes- patrones de autoridad de negociación), y 3) el modelo de autoridad inclusiva (relaciones dependientes y patrones de autoridad jerárquicos), véase Wrigt Deil, Spencer, Understanding Intergovernmental Relations, Belmont, Brooks-Cole Publishing Company, 1998, pp. 42-49, y García del Castillo, Rodolfo, Los municipios en México. Los retos ante el futuro, México, Porrúa-CIDE, 1999, pp. 31-33. Enrique Cabrero detalla, con base en el modelo de Wright, tres formas de entender los niveles de gobierno en un sistema federal. El primero, un federalismo jerárquico. El segundo es un federalismo dual en donde una 
La dependencia real que guardaban los estados respecto a la institución presidencial se puede apreciar en cuatro prerrogativas formales: 1) el presidente tenía la facultad de revocar a aquellos gobernadores que no atendieran sus demandas, a través del mecanismo de "desaparición de poderes"; 2) los gobernadores estaban sometidos a un sistema de control militar; 3) la presidencia, vía gobierno federal, concentraba la planificación económica y los recursos financieros del país, controlando la asignación de los mismos, en comparación a la raquítica estructura hacendaria de los estados, y 4) el presidente asignaba a los estados más avanzados, mayores cantidades monetarias; así la dependencia de los estados respecto del gobierno es un hecho político, militar y financiero, modelo que se reproducirá, en relación vertical, de los estados a los municipios. ${ }^{15}$

Si bien la subordinación de los estados a la presidencia pretendió someter los cacicazgos regionales y locales, a la vez, éstos cumplieron una doble función dentro del sistema; por un lado, como entes subordinados a la jerarquía federal, y por el otro, como factores reales de poder, que mantuvieron controladas a las facciones que quisieran oponerse al régimen. ${ }^{16}$ En este sentido, en la relación entre el gobierno federal y los estados predominaba una especie de contrato político, en el cual los cacicazgos locales se sometían a las decisiones del gobierno federal a cambio de prebendas y libertad de acción en las regiones que dominaban, inaugurando una cultura de relaciones personales, de parentesco y compadrazgos.

Es hasta las disputas por la apertura del régimen, así como las presiones económicas que éste sufría debido a las constantes crisis a mediados de la década de los setenta, que se mostraron los primeros síntomas de agotamiento del modelo político y económico en el que el régimen se sustentaba. Es así como, a partir de este momento, dos conceptos dominaban el escenario político: alternancia y descentralización. Para responder a las movilizaciones y luchas por una mayor apertura del régimen político, la democratización y pluralidad del régimen; para volver más eficiente la gestión gubernamental, la descentralización del aparato esta-

autonomía entre el orden federal y el orden local, entendiendo por este último el ámbito estatal, aquí el nivel municipal se encuentra circunscrito estrictamente dentro de las jurisdicciones de los estados miembros. Finalmente, un federalismo tripartito, en el cual la principal forma de relación entre las partes del sistema federal es la negociación. Creo que, hasta la alternancia política, existía en México un federalismo jerárquico que ha ido transformándose en un federalismo dual.

15 González Casanova, Pablo, La democracia en México, México, Era, 1995.

16 Idem. 
tal. ${ }^{17}$ Se afirmaba, entonces, que el proceso de descentralización respondería a la crisis del aparato estatal en la resolución de demandas inmediatas de la sociedad; sin embargo, entre la teoría y la praxis surgieron dos procesos alternos que destruyeron los hilos que sostenían el sistema político mexicano: de lado de la teoría, la descentralización del aparato estatal implicaba una democratización del sistema político; del lado de la práctica, la descentralización no implicó una democratización del sistema.

Dicha díada también operó en respuesta a la centralización de las competencias en materia electoral, que estaban controladas, de manera casi absoluta, por el ejecutivo, limitando su funcionamiento como un verdadero sistema colegiado de pesos y contrapesos. Las acciones en torno a este proceso se vieron reflejadas con la reforma constitucional de $1977 \mathrm{y}$ las reformas del Estado impulsadas en los años ochenta y noventa, cuando el proceso de democratización a nivel local era irreversible. ${ }^{18}$

Así, el federalismo, enarbolado por la Constitución de 1917, tendió a proclamarse, a finales del siglo XX, por la reformulación plural de un sistema de partidos políticos y el surgimiento de organismos electorales

17 Los ejes de la acción ciudadana, en la década de los setenta, giraron en torno a una apertura democrática donde las demandas radicaron en la resistencia a la imposición de candidatos; el respeto al voto y procesos electorales creíbles; uso correcto y transparente de los presupuestos públicos, y la definición pública de las políticas gubernamentales. Durante esta década se experimentaron formas ciudadanas que buscaban mantener y legitimar nuevas formas de interrelación y representación entre la sociedad y el Estado.

18 Las luchas municipalistas fueron la constante, a pesar de que en 1960 lo común seguía siendo que la vida política municipal estuviera supeditada al régimen corporativo del PRI y que las movilizaciones ciudadanas y los triunfos de la oposición fueran la excepción, podemos hablar que es, precisamente en estos años, cuando la debilidad del régimen para responder a las demandas sociales más inmediatas —democracia, bienestar y seguridad social- comenzó a mostrar sus primeros signos. En 1974 se enumeraron 26 municipios gobernados por la oposición, mostrando que esos triunfos fueron parte del empuje cívico producido desde el ámbito local, para 1975, el PAN ganaba su primer municipio en el Estado de México, el de Tultepec, a pesar de que le arrebataron el de Cocotitlán. Cfr. Rodríguez Wallenius, Carlos, Luchas municipalistas en México. Acciones ciudadanas por la democracia y el desarrollo local, México, UAM-X-Juan Pablos Editor, 2009. Ya para 1994, de los 2392 municipios en que estaba dividida la república, únicamente 227 estaban en manos de la oposición — 103 del PAN y 85 del PRD—, once más se encontraban en manos de consejos municipales, y en otros más había representantes de las fuerzas opositoras; además la oposición tenía $10.13 \%$ de los regidores de mayoría relativa y $78.82 \%$ de los 3526 regidores de representación proporcional. Cfr. Meyer, Lorenzo, "El municipio mexicano al final del siglo XX. Historia, obstáculos y posibilidades", en Merino, Mauricio (coord.), En busca de la democracia municipal. La participación ciudadana en el gobierno local mexicano, México, El Colegio de México, 1994. 
autónomos. Esos dos factores, junto con la tendencia a la homologación y la definición de competencias electorales claras en las legislaciones electorales estatales y la federal, dieron curso a la transformación del panorama electoral del país en un sentido federalista de sus aspectos legales y organizacionales.

Este rediseño del federalismo electoral se mantuvo vigente, con una clara definición de los ámbitos de competencia, subsidiariedad e independencia entre los organismos electorales autónomos locales y federal, hasta la reforma político electoral 2013-2014, la cual representa un revés a la rueda de la disputa por una forma de gobierno central o federal y coloca al equilibrio político en la ruta de una reconstrucción del entramado institucional electoral que defina claramente las nuevas competencias entre los niveles de gobierno.

\section{Vinculación entre el Instituto Nacional Electoral y los organismos públicos locales electorales}

La reforma político electoral 2013-2014 transformó al Instituto Federal Electoral y dio paso al Instituto Nacional Electoral como ente organizador de las elecciones federales y con injerencia en las facultades electorales del ámbito local. Si bien la esencia de la reforma estaba encaminada a la recentralización de las funciones electorales en una institución de carácter nacional, el resultado de ésta concluyó en un modelo que, por un lado, sobrecarga a la nueva institución de facultades que bajo el cobijo de un modelo federal le corresponden a los institutos autónomos locales, $\mathrm{y}$, por el otro, mantiene a los institutos locales con un cierto grado de autonomía e independencia.

Dicho resultado deviene de un alto grado de desconfianza ciudadana hacia las instituciones públicas de este país, ${ }^{19}$ se privilegió el miedo hacia los argumentos y presiones políticas sobre la injerencia e intervención de los gobernadores en los institutos electorales locales. No hay duda de que eso suceda en mayor o menor medida, independientemente de los colores partidistas; pero hay que decirlo con claridad, los mecanismos de fraude electoral de antaño ya no son posibles desde el ámbito insti-

19 Para mayor ahondamiento en el tema de confianza en las instituciones, consultar Moreno, Alejandro, Confianza en las instituciones, México en perspectiva comparada, México, Centro de Estudios Sociales y de Opinión Pública-ITAM, 2010. 
tucional de las autoridades electorales administrativas. Actualmente, el principal mecanismo es el clientelismo electoral que se logra por medio de dadivas de diferente naturaleza a los electores.

Lo decantado con esta reforma son las experiencias exitosas de vinculación interinstitucional registradas en los últimos años, que indican que la colaboración se ve favorecida cuando interactúan dos áreas operativas que, sin ser idénticas, sí son análogas en lo que se refiere a su ámbito competencial y su campo de acción técnica.

En el marco actual de la cooperación institucional, parece que las diferencias institucionales, en cuanto a dimensiones, denominaciones, duración en el cargo y mecanismos para la toma de decisiones, no han logrado ser superadas; de ahí que fuese necesario replantear el modelo electoral en función de una autoridad nacional que supervisara y reglamentara lo relativo al desarrollo de los procesos locales en un afán de homologación y centralización de los procedimientos electorales, sin que ello signifique una trasformación cultural de las prácticas y los temores anunciados.

Es así como, a partir de esta reforma, coexisten un instituto nacional, con facultades especiales sobre la integración y nombramiento de los consejos generales de los organismos públicos locales electorales, y la asunción, atracción y/o delegación de los procesos electorales locales, la fiscalización a los partidos políticos y la organización electoral, e institutos electorales locales con facultades limitadas, pero que conservan su autonomía e independencia del Instituto Nacional Electoral.

\section{Nombramiento y remoción de los consejeros locales}

La reforma prevé que el consejero presidente y los consejeros electoral de los OPLE sean designados por el Consejo General del INE, por un periodo de máximo siete años, de forma escalonada. ${ }^{20}$ El Consejo General

20 Es importante resaltar que el transitorio décimo de la Ley General de Instituciones y Procedimientos Electorales (LGIPE) señala a la letra: "Para los procesos electorales locales cuya jornada electoral se realice en 2015, el Consejo General del Instituto deberá desarrollar el proceso de designación de los integrantes de los Consejos Generales de los órganos locales, en los términos de los párrafos 1, 2 y 3 del inciso c) de la fracción IV del artículo 116 de la Constitución Política de los Estados Unidos Mexicanos, a más tardar el 30 de septiembre de 2014. Respecto a las demás entidades federativas, la elección se habrá de realizar con antelación al inicio de su siguiente proceso electoral. El Consejo General del Instituto deberá realizar los nombramientos de forma escalonada, en los siguientes términos: a) tres consejeros que durarán en su encargo tres años; 
está facultado para emitir la convocatoria pública para cada entidad federativa que corresponda, en la que deberán considerar expresamente los cargos y periodos a designar, plazos del proceso de designación, órganos ante quienes se deberán inscribir los interesados, requisitos, documentación y el procedimiento a seguir.

Para el proceso de designación, el Consejo General se apoya en la Comisión de Vinculación con los organismos públicos locales electoral, la cual tiene a su cargo el desarrollo, vigilancia y la conducción del proceso de designación. Para la difusión del proceso y recepción de documentación de los aspirantes, la Comisión se auxilia de los órganos desconcentrados del Instituto en las treinta y dos entidades federativas; asimismo, podría allegarse de la información complementaria para el desarrollo del proceso de designación de las propuestas de integración de cada uno de los consejos locales de los OPLE.

Una vez evaluadas las trayectorias de los participantes, la Comisión presentará al Consejo General del INE una lista de hasta cinco nombres por vacante en la entidad federativa. El Consejo General del Instituto designará por mayoría de ocho votos al consejero presidente y a los consejeros electorales de los OPLE, especificando para cada uno de ellos el periodo para el que serán designados.

Los requisitos para ser consejero electoral son: $a$ ) ser ciudadano mexicano por nacimiento, que no adquiera otra nacionalidad, además de estar en pleno goce de sus derechos civiles y políticos; $b$ ) estar inscrito en el Registro Federal de Electores y contar con credencial para votar vigente; c) tener más de 30 años de edad al día de la designación; d) poseer al día de la designación, con antigüedad mínima de cinco años, título profesional de nivel licenciatura; $e$ ) gozar de buena reputación y no haber sido condenado por delito alguno, salvo que hubiese sido de carácter no intencional o imprudencial; $f$ ) ser originario de la entidad federativa correspondiente o contar con una residencia efectiva de por lo menos cinco años anteriores a su designación, salvo el caso de ausencia por servicio público, educativo o de investigación por un tiempo menos de seis meses; g) no haber estado registrado como candidato ni haber desempeñado cargo alguno de elección popular en los cuatro años anteriores a la designación; $h$ ) no desempeñar ni haber desempeñado cargo de dirección nacional, estatal o municipal en algún partido político en los cuatro años anteriores a la designación; i) no estar inhabilitado para ejercer cargos públicos en cualquier institución pública federal o local; $j$ ) no haberse

b) tres consejeros que durarán en su encargo seis años; y c) un consejero que durará en su encargo siete años". 
desempeñado durante los cuatro años previos a la designación como titular de secretaría o dependencia del gabinete legal o ampliado tanto del gobierno de la federación o como de las entidades federativas, ni subsecretario u oficial mayor en la administración pública de cualquier nivel de gobierno; $k$ ) no ser jefe de gobierno del Distrito Federal, ni gobernador, ni secretario de gobierno o su equivalente a nivel local; $l$ ) no ser presidente municipal, síndico o regidor o titular de dependencia de los ayuntamientos, y $\mathrm{m}$ ) no ser ni haber sido miembro del Servicio Profesional Electoral Nacional durante el último proceso electoral en la entidad.

Asimismo, el Consejo General del INE tiene la facultad de remover a los consejeros electorales de los OPLE por incurrir en alguna de las siguientes causas graves: $a$ ) realizar conductas que atenten contra la independencia e imparcialidad de la función electoral, o cualquier acción que genere o implique subordinación respecto de terceros; $b$ ) tener notoria negligencia, ineptitud o descuido en el desempeño de las funciones o labores que deban realizar; $c$ ) conocer de algún asunto o participar en algún acto para el cual se encuentren impedidos; $d$ ) realizar nombramientos, promociones o ratificaciones infringiendo las disposiciones generales correspondientes; $e$ ) emitir opinión pública que implique prejuzgar sobre un asunto de su conocimiento y no haberse excusado del mismo; f) dejar de desempeñar injustificadamente las funciones o las labores que tengan a su cargo, $y g$ ) violar de manera grave o reiterada las reglas, lineamientos, criterios y formatos que emita el Instituto. ${ }^{21}$

\section{Las facultades especiales del INE}

En materia de capacitación y organización electoral se otorgan al INE amplias atribuciones. Con base en el acuerdo de su Consejo General, del 14 de julio de 2014, el INE reasume las atribuciones establecidas en el artículo 32 de la LGIPE, que de inicio estaban delegadas a los OPLE por virtud del artículo octavo transitorio de la reforma constitucional político electoral, en cuanto a la ubicación de casillas, capacitación de funcionarios de mesas directivas de casilla y designación de esos funcionarios, tanto en procesos comiciales federales como en los locales, aun en aquellos casos en los que no haya una elección concurrente.

${ }^{21}$ En términos de la Base V, Apartado B, inciso a, numeral 5 del artículo 41 de la Constitución. Para los efectos de este inciso se considera violación grave, aquella que dañe los principios rectores de la elección de que se trate, párrafo 2 del artículo 102 de la LGIPE. 
En materia de geografía electoral, se presenta un tema de elevada complejidad técnica: la delimitación de los espacios geoelectorales de los distritos locales. Hay a quien le parece que es posible hacer compatibles los que corresponden al ámbito local y al federal. A primera vista, desde el escritorio, pareciera una posibilidad viable. Muchos dirán que resulta perfectamente posible integrar, completos, distritos electorales locales y municipios en los distritos federales. Pero es necesario tomar en cuenta que son los congresos estatales los que definen el número de distritos locales y es indispensable tomar en cuenta características regionales culturales y étnicas, en muchas entidades del país.

De igual forma, la reforma crea un Servicio Profesional Electoral Nacional, que regulará las reglas de selección, ingreso, capacitación, profesionalización, promoción, evaluación, rotación, permanencia y disciplina de los servidores públicos de los órganos ejecutivos y técnicos, tanto del INE, como de los organismos públicos locales, y será desarrollada por la legislación secundaria y por los reglamentos que apruebe el Consejo General del INE. Si bien el tema se encuentra poblado de interrogantes, existen exigencias claramente identificables que la Comisión del Servicio Profesional Electoral Nacional y el Consejo General del INE tendrán que acatar. Entre estas exigencias están que la creación de un servicio electoral nacional no implica, en modo alguno, una modificación de las relaciones laborales que los servidores públicos electorales han entablado, hasta la fecha, con el Instituto Federal Electoral o con los institutos locales. Sin embargo, será menester el esclarecimiento de los requisitos y procedimientos conforme a los cuales el personal podrá circular por el sistema nacional o solo por un subsistema local. De ahí que la identificación de los desafíos en este campo y la generación de alternativas pertinentes constituyan elementos cruciales para el éxito del modelo y para su efectiva contribución a la celebración de comicios de mayor calidad democrática.

En materia de fiscalización del origen, monto y destino de los recursos que emplean los partidos políticos, la reforma prevé que la atribución del INE se encuentra limitada al ámbito temporal y geoelectoral de los procesos comiciales, locales y federales. Ocurre, sin embargo, que los organismos locales conservan la facultad de otorgar prerrogativas y que éstas no se encuentran constreñidas al financiamiento de campaña. Pareciera que bajo el principio alusivo de que el ente que provee recursos tiene de modo implícito o explícito, el derecho y deber de verificar su aplicación, los organismos locales podrán seguir fiscalizando los financiamientos que otorguen para el sostenimiento de las actividades ordinarias permanen- 
tes de los partidos políticos y para lo que comúnmente se conoce como actividades específicas. Empero, surge el riesgo de que estos recursos no sean debidamente compartimentados y se empleen subrepticiamente en las campañas. Así, las exigencias de coordinación entre los dos ámbitos crecen exponencialmente $\mathrm{y}$, por ende, deberán construirse mecanismos novedosos y eficaces de fiscalización. El caso es que, de no actuarse con visión innovadora, las dificultades técnicas del tema podrían dar lugar a desbordamientos del ámbito atributivo y a crecimientos descontrolados de la estructura del INE abocada a esas labores.

Asimismo, la reforma otorga al Consejo General del INE las facultades de: 1) asunción directa de la realización de las actividades propias de la función electoral que corresponden a los órganos electorales locales; 2) delegación, en los órganos electorales locales, de las atribuciones relacionadas con la organización electoral, sin perjuicio de reasumir su ejercicio directo en cualquier momento, y 3 ) atracción a su conocimiento de cualquier asunto de la competencia de los órganos electorales locales, por su trascendencia o para sentar un criterio de interpretación.

Se entiende por asunción la atribución del Instituto de asumir directamente la realización de todas las actividades propias de la función electoral que corresponden a los OPLE, ya sea total o parcial. ${ }^{22} \mathrm{La}$ asunción total de la competencia de una elección solo será procedente cuando se acredite fehacientemente en el procedimiento, alguno de los siguientes supuestos: a) que existan diversos factores sociales que afecten la paz pública o pongan a la sociedad en grave riesgo en la entidad federativa que, a decir del peticionario, afectan los principios constitucionales electorales de imparcialidad, certeza, legalidad, objetividad y equidad en la contienda electoral e impiden por lo tanto, que se lleve a cabo la organización pacífica de la elección por el OPLE competente, y b) que no existan condiciones políticas idóneas, por injerencia o intromisión comprobable de algunos de los poderes públicos en la entidad federativa que afecten indebidamente la organización del proceso electoral por el OPLE, al no poderse realizar todas las etapas del proceso electoral por este organismo, con imparcialidad. ${ }^{23}$ Los procedimientos de asunción se iniciarán a petición fundada y motivada ante el Instituto, hasta antes del inicio del proceso electoral, de al menos cuatro de sus consejeros, o de la mayoría del

22 En términos del Apartado C, de la Base V del artículo 41 de la Constitución y del párrafo 2 del artículo 120 de la LGIPE.

23 Párrafo 2 del artículo 121 de la LGIPE. 
Consejo del OPLE. ${ }^{24}$ Por su parte, la asunción parcial de alguna actividad propia de la función electoral que le corresponde al OPLE, podrá llevarse a cabo con la aprobación de la mayoría de votos de su Consejo General y se resolverá por mayoría de cuando menos ocho votos del Consejo General del INE. ${ }^{25}$

Por atracción se entiende la atribución del Instituto de atraer a su conocimiento cualquier asunto de la competencia de los OPLE, cuando su trascendencia, es decir la naturaleza intrínseca del asunto permita que éste revista un interés superlativo reflejado en la posible afectación o alteración del desarrollo del proceso electoral o de los principios de la función electoral local, así lo determine. ${ }^{26}$ En el caso de la facultad de atracción, la petición sólo podrá formularse por al menos cuatro de los consejeros electorales del Instituto o la mayoría del Consejo General del OPLE. El Consejo General ejercerá la facultad de atracción siempre que exista la aprobación de una mayoría de cuando menos ocho votos. ${ }^{27}$

La delegación de funciones del Instituto en los OPLE tendrá carácter excepcional. Para el ejercicio de esta facultad, el Consejo General deberá valorar la evaluación positiva de las capacidades profesionales, técnicas, humanas y materiales del OPLE, para cumplir con eficiencia la función. La delegación se realizará antes del inicio del proceso electoral local correspondiente, requerirá del voto de al menos ocho consejeros electorales y se realizará de forma específica en cada caso para un OPLE determinado. Finalizado el proceso electoral, cesarán los efectos de la delegación. El Instituto podrá reasumir la función que haya sido delegada antes de que finalice el proceso electoral respectivo, siempre y cuando se apruebe por la misma mayoría de ocho votos.

\section{Reflexiones finales}

Si bien es cierto que la reforma al sistema electoral generó un nuevo modelo electoral que presenta innovaciones relevantes, no deber perderse de vista la importancia que esta reforma tiene sobre la transformación

\footnotetext{
24 Párrafo 3 del artículo 121 de la LGIPE.

25 Artículo 123 de la LGIPE.

26 En términos del inciso $c$, del Apartado C, de la Base V del artículo 41, de la Constitución y del párrafo 3 del artículo 120 de la LGIPE.

27 En términos de los párrafos 1-4 del artículo 124 de la LGIPE.
} 
del federalismo electoral, que en el fondo implica una manera distinta de entender los componentes del sistema electoral mexicano y de sus interacciones. Alude, por supuesto, a órganos del Estado con encomiendas y alcances específicos, pero también implica desafíos en cuanto a la forma como debe concebirse el nuevo modelo electoral y las estructuras administrativas que deben crearse para elevar la calidad democrática de los procesos de transmisión legal, pacífica y legítima del poder, para fortalecer el sistema democrático, y propiciar el entorno indispensable que asegure la convivencia pacífica y enriquecedora, y el bienestar de la población.

Queda la tarea de realizar una evaluación pormenorizada, derivada de la experiencia que se adquiera de los procesos electorales 2014-2015, respecto de las ventajas o desventajas del diseño organizacional existente. Entretanto, una vía adecuada para el fortalecimiento del sistema de organismos electorales sigue siendo el favorecer los espacios de colaboración entre organismos y propiciar la convergencia de los marcos legales, sin renunciar a las dinámicas locales. Esta es, por otra parte, la fórmula que resulta de la condición del país como una república federal, democrática y representativa. Un federalismo electoral, consciente de que la distribución de competencias no implica en modo alguno la construcción de compartimentos estancos, sino presupone oportunidades de colaboración, podría constituir la plataforma ideal para construir una institucionalidad electoral de orden superior.

Debe quedar claro que el nuevo modelo electoral puede propiciar tensiones entre los actores políticos locales, que pueden llegar al conflicto, y los institutos electorales locales y el INE. Lo anterior derivado de la merma de la soberanía estatal y de la tenue línea que, en algunos temas, delimita los ámbitos de atribuciones locales y nacionales.

\section{Bibliografía}

Cabrero Mendoza, Enrique, "El panorama de la descentralización en México: ¿hacia qué tipo de federalismo evolucionar?", Avances y pendientes para fortalecer el federalismo, México, CESOP, 2007.

-_- , Para entender el federalismo en los Estados Unidos Mexicanos, México, Ediciones Nostra, 2007.

Córdova, Arnaldo, La formación del poder político en México, México, Era, 1978. 
Constitución Política de los Estados Unidos Mexicanos, Decreto en materia política-electoral publicado en el Diario Oficial de la Federación el 10 de febrero de 2014.

García del Castillo, Rodolfo, Los municipios en México. Los retos ante el futuro, México, Porrúa-CIDE, 1999.

González Casanova, Pablo, La democracia en México, México, Era, 1995.

Hernández Chávez, Alicia, "Las tensiones internas del federalismo mexicano", ¿Hacia un nuevo federalismo?, México, FCE, 1996.

Ley General de Instituciones y Procedimientos Electorales (LGIPE), Diario Oficial de la Federación, 27 de mayo de 2014.

Medina Peña, Luis, Invención del sistema político mexicano. Forma de gobierno y gobernabilidad en México en el siglo XIX, México, FCE, 2007. Merino, Mauricio, Gobierno local, poder nacional. La contienda por la formación del Estado mexicano, México, El Colegio de México, 2005.

Meyer, Lorenzo, "El municipio mexicano al final del siglo XX. Historia, obstáculos y posibilidades", en Merino, Mauricio (coord.), En busca de la democracia municipal. La participación ciudadana en el gobierno local mexicano, México, El Colegio de México, 1994.

Moreno, Alejandro, Confianza en las instituciones: México en perspectiva comparada, México, CESOP-ITAM, 2010.

Reyes Heroles, Jesús, "El federalismo", El liberalismo mexicano, III. La integración de las ideas, México, FCE, 2007.

Rodríguez Wallenius, Carlos, Luchas municipalistas en México. Acciones ciudadanas por la democracia y el desarrollo local, México, UAMX-Juan Pablos Editor, 2009.

Sordo, Reynaldo, "El liberalismo, representatividad, derecho al voto y elecciones en la primera mitad del siglo XIX en México", en Moreno Bodet, Margarita y GonzÁLEz, Refugio (coords.) La génesis de los derechos humanos, UNAM, Instituto de Investigaciones Jurídicas, 2006.

Wrigt DeIL, Spencer, Understanding Intergovernmental Relations, Belmont, Brooks-Cole Publishing Company, 1998. 